\title{
Exploring the clumped and bulk isotopic systematic of carbonates near two deep-water cold seeps offshore Nova Scotia, Canada
}

\author{
JOSUÉ J. JAUTZY ${ }^{1}$, MARTINE M. SAVARD ${ }^{1}$, CALVIN \\ CAMPBELL $^{1}$ AND ADAM W. A. MACDONALD ${ }^{2}$ \\ ${ }^{1}$ Natural Resources Canada \\ ${ }^{2}$ Nova Scotia Department of Energy and Mines \\ Presenting Author: josue.jautzy@canada.ca
}

Clumped isotopes $\left(\Delta_{47}\right)$ excess measurements in carbonates is becoming a widespread isotopic geothermometer, which also casts the precipitating fluid $\delta^{18} \mathrm{O}$ composition. The measurement of clumped isotopic abundances in authigenic carbonates near marine cold seeps has revealed an unprecedented range of isotopic ordering, and several explanations have been put forward to account for the various disequilibrium signals observed. Here we report $\delta^{13} \mathrm{C}, \delta^{18} \mathrm{O}$ and $\Delta_{47}$ measurements performed on two sediment core profiles from two deeply-seated cold seeps (water depth $>2400 \mathrm{~m}$ ), on the platform margin offshore Nova Scotia. The cores contain several indications of hydrate presence. Data obtained from sub-surface depth varying between 34 and $235 \mathrm{~cm}$ reveal a clear $\mathrm{CH}_{4}$ oxidation signal in the investigated calcites, associated with $\Delta_{47}$ and $\delta^{18} \mathrm{O}$ values mostly in apparent disequilibrium with seafloor conditions. Here, we will discuss the observation of higher apparent $\Delta_{47}$ and $\delta^{18} \mathrm{O}$ disequilibrium at depth in comparison to surficial samples. We will compare them to results from other cold seep settings and explore the possible causes of these isotopic patterns. 